\title{
Contos de fadas: de sua origem à clínica contemporânea
}

Fairy tales: from their origin to contemporary clinic

Cuento de hadas: de su origen a la clínica contemporánea

\author{
Raquel Elisabete Finger Schneider * \\ Sandra Djambolakdijan Torossian*
}

\begin{abstract}
Resumo
Os contos de fadas são histórias difundidas desde a Antiguidade e têm comprovada influência e relevância entre infância também na contemporaneidade. Esta revisão de bibliografia visa a contribuir para os estudos da psicanálise no que tange ao entendimento analítico dessas preciosas histórias da literatura infantil, em especial quanto à sua aplicabilidade terapêutica na clínica psicológica. Inicialmente, percorremos a literatura em busca de subsídios que elucidem a sua origem e que sustentem o uso dos contos na pesquisa em psicologia clínica. Na sequência, sustentamos a aplicabilidade dos contos de fada na prática clínica, enfocada por diversas correntes teóricas. Na clínica psicanalítica contemporânea, faz-se corriqueiro o uso de contos de fadas com crianças, para diagnóstico e tratamento, quando são usados como uma forma de expressão e simbolização do sofrimento.
\end{abstract}

Palavras-chave: contos de fada; psicanálise; aplicabilidade terapêutica.

\begin{abstract}
Fairy tales have been known since antiquity and their influence on and relevance to children nowadays are unquestionable. The objective of this bibliographic review is to contribute to psychoanalytical studies in what concerns the analytical understanding of those rich stories of children's literature, especially regarding their therapeutic applicability to psychological clinic. First we reviewed the literature in order to find material to elucidate their origin and to advise their use in clinical psychology research. We then proceeded to recommend the applicability of fairy tales to clinical practice, with basis on in different theoretical views. In contemporary psychoanalytic clinic, it is common to use fairy tales with children for diagnosis and treatment, as a form of expression and symbolization of suffering.
\end{abstract}

Key words: Fairy tales; Psychoanalysis; Therapeutic applicability.

\footnotetext{
Texto recebido em agosto de 2008 e aprovado para publicação em agosto de 2009.

Mestra em Psicologia Clínica pela Universidade do Vale do Rio dos Sinos - Unisinos-RS, e-mail: raquel.schneider@terra.com.br.

** Doutora em Psicologia pela Universidade Federal do Rio Grande do Sul - UFRGS, e-mail: djamb@terra.com.br.
} 


\section{Resumen}

Los cuentos de hadas son historias difundidas desde la antiguedad y también en la contemporaneidad poseen una relevancia e influencia para la infancia. La revisión bibliográfica que aquí presentamos tiene como objetivo contribuir para los estudios del psicoanálisis con respecto al entendimiento analítico de estas preciosas historias de la literatura infantil, especialmente por su aplicabilidad terapéutica en la clínica psicológica. Iniciamos un recorrido por la literatura en busca de subsidios que eluciden su origen y que sustenten su utilización en el ámbito de la pesquisa en psicología clínica. A continuación sustentamos la aplicabilidad de los cuentos de hadas en la práctica psicológica, enfocándola a partir de diferentes corrientes teóricas. El uso de cuentos de hadas con niños es habitual en lo que se refiere al diagnóstico y al tratamiento en la clínica psicoanalítica contemporánea cuando son utilizados como una forma de expresión y simbolización del sufrimiento.

Palabras clave: cuento de hadas, psicoanálisis, aplicabilidad terapéutica

\section{Os contos de fadas e a infância}

Considerando que os contos de fadas são histórias difundidas desde a Antiguidade, com comprovada influência e relevância para o público infantil também na contemporaneidade, esta revisão de bibliografia visa a contribuir para os estudos da aplicabilidade terapêutica dessa literatura.

Percorremos a literatura em busca de subsídios que sustentassem o uso dos contos na pesquisa em Psicologia clínica. Realizamos uma "garimpagem arqueológica" dos contos de fadas e, no decorrer das "escavaçōes", fomos surpreendidos com fragmentos, achados inusitados e peças raras. Dessa "garimpagem", resultaram inúmeros achados singulares e estabeleceu-se uma necessidade seletiva.

Procuramos organizar este artigo em torno de dois principais eixos. Num primeiro momento, trataremos especificamente da pesquisa dos contos de fadas, abordando a tradição oral e artesanal do Período Medieval até a contemporaneidade, com autores pioneiros, como Charles Perrault, o brasileiro Monteiro Lobato, situando as contribuiçôes mais recentes da literatura que apontam para um processo singular de subjetivação dos corpos infantis. Num segundo ponto, sustentamos a aplicabilidade dos contos de fadas na clínica psicológica, recorrendo a diversas correntes teóricas.

\section{$2 \mathrm{Na}$ mágica viagem dos contos de fadas, um pouco de história}

O surgimento dos contos de fadas perde-se no tempo. A literatura registra que são histórias transmitidas oralmente de geração a geração e que, mesmo com toda a tecnologia existente, mantêm seu espaço de destaque narrativo 
junto à infância. Já não se reservam apenas à função de distração ou de acalanto ao sono das crianças, mas seu poder se expressa na magia e na fantasia que despertam no infante. Tornam-se, assim, alvo do estudo científico de diversas ciências do conhecimento e do desenvolvimento infantil, como a Pedagogia, a Psicologia e, em especial, a psicanálise.

Muito se escreveu e ainda se escreve sobre essa modalidade de literatura, numa tentativa de abordar as questôes pertinentes ao seu entendimento. Há registros bastante antigos sobre os contos e seu uso nas mais diversas culturas. Os contos de fadas, especialmente, têm encantado várias gerações em diferentes países e, antes mesmo de serem registrados pela escrita na forma como os conhecemos, eram responsáveis pela formação coletiva da espiritualidade e da cultura de inúmeros povos (Melli \& Giglio, 1999; Oliveira, 1993).

A literatura, embora não seja unânime, aponta para a origem céltica (século II a.C.) dos contos de fadas. Hisada (1998) aborda os escritos de Platão, nos quais mulheres mais velhas empregavam suas histórias recheadas de simbologia na educação de crianças. A autora cita Apuleio, filósofo do século 2 d.C., e seu romance "O Asno de Ouro", que, em muito, lembra o conto "A Bela e a Fera". Também no Egito, refere Hisada (1998), nos papiros dos irmãos Anúbis e Bata, foram encontrados registros de contos de fadas. Ferreira (1991) relata que os povos da Antiguidade conheciam o universo fantástico existente nos contos. Seu enredo é tramado por tecidos de refinadas matrizes do imaginário humano, cuja linguagem, repleta de significados simbólicos e de metáforas, tem a capacidade de interligar o consciente e o inconsciente.

Os contos, em sua essência, não eram destinados ao universo das crianças, uma vez que as histórias eram recheadas de cenas de adultério, canibalismo, incesto, mortes hediondas e outros componentes do imaginário dos adultos. Souza (2005) faz menção aos contos, descrevendo-os como histórias que narravam o destino dos homens, suas dificuldades, seus sentimentos, suas inter-relaçóes e suas crenças no sobrenatural. Eram relatados por narradores profissionais, os quais herdavam essa função dos antepassados, ou como uma simples tradição transmitida de pessoa para pessoa. Geralmente, as narraçóes ocorriam em campos de lavouras, reuniōes sociais, nas salas de fiar, casas de chá, nas aldeias ou nos demais espaços em que os adultos se reuniam (Radino, 2001, 2003).

Originalmente construídos para o universo adulto, a partir da "descoberta da infância" (Ariés, 1981, p. 11), passam a sofrer adaptaçôes no sentido de contemplarem as necessidades das crianças, bem como de sua vida imaginária. Os contos se configuravam em artifícios fascinantes à fantasia infantil, 
narrados pelas amas, governantas e, ou, pelas "cuidadoras" das crianças, que se incumbiam de contar e perpetuar histórias de origem popular, construídas com base na cultura do povo.

Os contos de fadas distinguem-se das demais histórias infantis por características como o uso de magia e encantamentos, um núcleo problemático existencial no qual o herói ou a heroína busca sua realização pessoal e, finalmente, a existência de obstáculos a serem enfrentados pelos heróis (Caldin, 2002; Oliveira, 2001; Radino, 2003; Turkel, 2002). Para Bettelheim (1980), é característica desses contos a presença de um dilema existencial de forma sucinta e categórica. Cashdan (2000) afirma que o conto de fada tem quatro etapas: a travessia, a viagem ao mundo mágico; o encontro com o personagem do mal ou o obstáculo a ser vencido; a dificuldade a ser superada; e a conquista (destruição do mal); a celebração da recompensa.

Os contos se caracterizam por serem uma narrativa cujos personagens heróis e, ou, heroínas enfrentam grandes desafios para, no final, triunfarem sobre o mal. Permeados por magias e encantamentos, animais falantes, fadas madrinhas, reis e rainhas, ogros, lobos e bruxas personificam o bem e o mal. No conto de fadas, tapetes voam, galinhas põem ovos de ouro, pés de feijão crescem até o céu, enfim, traz-se à tona o inverossímil, e é essa magia que instiga a mente humana (Bettelheim, 1980; Hisada, 2003; Radino, 2003).

$\mathrm{Na}$ forma como atualmente são conhecidos, os contos de fadas surgiram na Europa, especialmente na França e na Alemanha, no final do século XVII e XVIII (Lubetsky, 1989). O momento histórico se configurava com a Inglaterra, que passava pela sua segunda Revolução Industrial e detinha o controle capitalista da época, e a Igreja, que atravessava a Contrarreforma. Os contos daquele período eram permeados pela "Moral Vitoriana", de uma sociedade repressiva quanto às questôes sexuais, considerando que os conceitos de infância e de educação também não eram vigentes naquela época.

Entre os precursores na coleta dessas narrativas populares, os contos, encontra-se Perrault (1628-1703). Esse autor registrava as histórias com base em narraçóes populares, adaptava-as e as floreava conforme a necessidade da corte francesa da época, acrescentando proeminências e censurando detalhes da cultura pagã e da sexualidade humana. Seus contos, até mesmo as versões infantis, são recheados de uma mensagem moral explícita, normalmente colocada em apêndices sob forma de versos. A mensagem moral, conforme descreve Perrault, tinha como finalidade servir de orientação e de ensinamento aos que a ouvissem. Apesar de escrever contos de fadas, em suas histórias, as fadas são personagens pouco presentes. Perrault preferiu introduzir figuras 
humildes, como lenhadores, serviçais, aldeões, damas e cavaleiros. Outro aspecto relevante de seus contos mostra-se na escolha em retratar as lindas paisagens francesas, suas campinas, a atmosfera desses lugares. Sua obra mais famosa, intitulada Contos da Mamãe Gansa, veio ao público em meados de 1697 e apresenta uma versão da história de Chapeuzinho Vermelho, ressalvando o fato de o Lobo sair vitorioso ao final. Também integram essa coletânea contos como A Bela Adormecida, Barba Azul, O Gato de Botas, As Fadas, Cinderela, O Pequeno Polegar (Figueiredo, 1998, Góes, 1991; Lima, 2000; Lubetsky, 1989; Oliveira 2001; Radino, 2003; Silva, 2004; Souza, 2005).

Há registros na literatura consultada de que o movimento romântico instaurado na época trouxe aos contos um sentido mais humanitário (Góes, 1991). Dessa forma, a violência presente nos contos de Perrault concede espaço ao humanismo que, de forma delicada, perpassa as histórias escritas pelos irmãos Grimm, preconizando a solidariedade e o amor ao próximo. Os aspectos mais agressivos ainda se mostram presentes, personificados principalmente na figura do Lobo e da Bruxa, porém, ao final, impera a esperança, a confiança na vida e o indispensável final feliz.

Inúmeros contos foram registrados também pelos alemães Jacob Grimm (1785-1863) e Wilhelm Grimm (1786-1859), mais conhecidos como os Irmãos Grimm. Filósofos e estudiosos da mitologia germânica e da história do direito alemão, passaram a coletar e a estudar uma grande massa de textos e de histórias populares medievais de origem germânica e francesa contadas oralmente (Robinson, 2004). Como consequência, publicaram (1812-1822) 210 histórias em três volumes para crianças e adultos. Seus contos são povoados por madrastas malvadas, príncipes encantados, casas de chocolate, bruxas perversas, feras, entre outros personagens singulares. Entre os contos que foram traduzidos para o português, destacam-se: A Bela e a Fera, Os Músicos de Bremen, Branca de Neve e os Sete Anóes, Chapeuzinho Vermelho e Gata Borralheira. Da Alemanha, de 1850 até hoje, os contos de Grimm traduzem histórias de lendas e fábulas populares que os irmãos ouviram viajando por aquele país. À diferença de Perrault, registraram essas histórias nas versões originais, sem adaptações e liçôes de moral explícitas (Hisada, 1998; Lima, 2000; Lubetsky, 1989; Oliveira, 2001; Radino, 2003; Silva, 2004; Souza, 2005).

O poeta e novelista dinamarquês Hans Christian Andersen (1805-1875), considerado por muitos como o paida literatura infantil, destacou-se justamente por escrever seus contos diretamente para as crianças. Diferente dos demais autores da época, que adaptavam as histórias à realidade infantil, Andersen criou uma narrativa destinada para esse público. Fortemente influenciado pelas 
histórias narradas por seu pai, um humilde sapateiro, Andersen utilizou-se do sofrimento observado nas crianças menos favorecidas e pobres para rechear seus contos. Soube como ninguém retratar os desejos da população, fazendo com que suas histórias assumissem a estrutura de crônicas tristes, muitas vezes com conteúdos extraídos de seu próprio cotidiano, inaugurando, assim, o que hoje denominamos de literatura infantil (Corso \& Corso, 2005, 2006; Lima, 2000; Radino, 2003; Souza, 2005).

A literatura assinala três importantes vértices que tornam a obra de Andersen inédita: a criança retratada por meio dos personagens, brinquedos que ganham vida e histórias nas quais o papel principal é ocupado por uma criança. Esses personagens infantis que falam pelas crianças expressando seus sofrimentos e temores têm na obra do Patinho Feio sua representação mais significativa. Alguns autores aludem a esse conto, em especial, como sendo o retrato da vida do escritor e seu difícil percurso. Seus contos, como o Soldadinho de Chumbo, trazem a animação de objetos como os brinquedos, caracterizando a impotência dos pequenos, cheios de desejos, porém não escutados e não compreendidos. E, finalmente, credita um papel de protagonista às crianças, como acontece no conto A Roupa Nova do Imperador, narrativa que delega a uma criança a importante tarefa de alertar o Imperador sobre a falta das vestes dele. Em seus contos, encontramos também sereias, fadas e animais fantásticos. Ao longo da obra, é possível perceber os valores morais sutilmente embutidos nas histórias, assim como a ausência de jargóes como "e foram felizes para sempre". É atribuída a Andersen a autoria de aproximadamente 156 contos (Corso \& Corso, 2005, 2006; Lima, 2000; Radino, 2003; Souza, 2005).

Ao longo da história, destacaram-se também as importantes contribuições do inglês Lewis Carroll, autor de Alice no País das Maravilhas e Do Outro Lado do Espelho; do italiano Carlo Collodi, que, em 1881, escreveu Pinocchio; do escocês James Berrie, descrevendo as aventuras do levado Peter Pan; e do americano L. Frank Baum, autor de $O$ Mágico de $O z$. Esses contos infantis são elencados por alguns dos críticos literários, a exemplo de Corso \& Corso (2006), como contos modernos, em detrimento dos clássicos escritos na Europa do século XVII. O que se sabe ao certo é que, clássicos ou modernos, os contos infantis embalam a fantasia e a imaginação das crianças, sobrevivendo aos séculos e sendo apreciados e difundidos até os dias atuais.

No Brasil e em Portugal, os contos de fadas como são conhecidos hoje surgiram no final do século XIX sob o nome de Contos da Carochinha. Somando, aproximadamente, 61 contos populares, passaram a ser denominados contos de fadas somente no final do século XX. Radino (2003) aponta para o fato 
de o termo "carochinha" significar carocha ou bruxa, concedendo-lhes, dessa forma, uma conotação nociva de mentira.

Como destaque brasileiro na produção de contos de fadas, podemos citar as sofisticadas histórias de Monteiro Lobato, nas quais bonecas falam e sabugos de milho se transformam em geniais cientistas. É atribuída a esse autor a publicação de 26 títulos direcionados ao público infantil, influenciando autores contemporâneos como Ziraldo, Ana Maria Machado e Ruth Rocha. Radino (2003) enfatiza que, para Monteiro Lobato, o livro, a história ou mesmo o conto de fadas são vividos e experimentados pelas crianças como um agente transformador, auxiliando-as na construção de sua crítica, de sua criatividade e, sobretudo, de sua liberdade, pois, neles, elas aprendem brincando.

Autores mais recentes (Hillesheim, 2006; Zilberman, 1998) analisam a construção da infância e do sujeito a partir da literatura infantil contemporânea. Eles apontam a potencialidade da literatura de subjetivar as crianças, uma vez que esses textos constroem um conceito de infância com o qual as crianças contemporâneas se conectam. Hillesheim (2006) aponta que os contos desenham configurações de infância, preceituando falas nas quais culpa, irracionalidade, inocência operam sobre o disciplinamento e o controle dos corpos infantis. Concomitantemente, por operarem como um dispositivo artístico, possibilitam ruptura, transgressão e resistência, instaurando o "estranhamento". Zilberman (1998) refere que a literatura infantil contemporânea se ocupa de uma linha narrativa que retrata personagens que internalizam várias crises do mundo social. Tais modificações denotam, inclusive, uma modificação na noção de infância, configurando-se essa em uma imagem de criança crítica da contemporaneidade.

\section{Os contos de fadas como dispositivo de intervenção na prática clínica}

Os contos, desde sua origem, já exerceriam função terapêutica, fato que explicaria sua permanência e transmissão transgeracional ao longo dos séculos (Gutfreind, 2003). Conforme descrito por Dieckmann (1986), e mais recentemente por Hisada (1998) e Melli \& Giglio (1999), os contos de fadas eram amplamente usados na medicina hindu como método terapêutico para pessoas que apresentavam problemas mentais. A elas, era oferecido o conto com o objetivo de estimular sua meditação. $\mathrm{O}$ conto é vivido como personificação de formações e evoluções interiores da mente, pois usam a mesma linguagem que o inconsciente.

Na clínica psicanalítica contemporânea, faz-se corriqueiro o uso de histórias 
infantis com crianças e adultos para diagnóstico e tratamento (Bernstein, 1999; Bettelheim, 1980; Brandt, 1983; Bruder, 2004; Caillé \& Rey, 1990; Castello, 1999; Catheline-Antipoff \& Soulayrol, 1994; Chauí, 1984; Davies, 1988; Dieckmann, 1997; Ellis, 1990; Erle, 1999; Fagulha, 1999; Ferreira, 1991; Ferro, 1995; Garcia \& Garcia, 2005; Goldmann, 2001; Gutfreind, 2000, 2002, 2003; Hisada, 1998; Ishikawa et al., 1990; Luz \& Zanetti, 2003; Machado, 1988; Roberge, 2002; Robinson, 1986; Safra, 2005; Schmid et al., 2002; Silva \& Fachin, 2002; Souyouldzoglou, Anasiassia, Coulacoglou, \& Gardiner, 1999; Sussenbacher, 1982; Stube, 2001; Turkel, 2002; Tychey, 1993; Zago, 1998).

O conto favorece a introspecção, afirma Caldin (2004), pois, por intermédio dele, a criança tem a possibilidade de pensar sobre seus sentimentos e tem a esperança de que o sofrimento que a acomete venha a ser passageiro. A introspecção, pela literatura, atrai as emoções do ouvinte ou do leitor e tem a capacidade de liberá-las. O autor faz menção especial à criança frágil e ou mesmo doente, pois essa se preocupa em demasia consigo mesma e, portanto, aprecia os textos que falam de seus problemas. A universalização dos problemas é uma garantia de que ela não se encontra sozinha na sua dor. Considera-se que a leitura ou a narração da história produz reflexões, mesmo quando a criança se encontra sozinha no seu quarto, de dia ou à noite; ao se lembrar da história, pode sentir-se mais reconfortada. Os contos são fonte de prazer para as crianças tanto pelo ouvir quanto pela sua representação. Prazer produz alegria, e alegria é terapêutica, afirma Caldin (2004).

O discurso literário abre perspectivas para a percepção do mundo do ponto de vista da infância, traduzindo suas emoçôes, seus sentimentos, suas condições existenciais em linguagem simbólica que efetue a catarse e promova um ensaio geral da vida. Favorecem a socialização pela participação em grupo, e sabe-se que o convívio social mostra-se importante instrumento na cura de doenças. Há que se salientar que, ao conciliar literatura e terapia, o narrador, após a história, deve incentivar a criança a trocar ideias e a realizar um exercício de reflexão entre o real e o imaginário (Caldin, 2004).

Monaci (1990) afirma a importância da narração de contos e histórias não só num sentido terapêutico, mas para a estimulação do repertório de soluçóes adaptativas de conflitos, de entendimento de sentimentos, de motivações, de solidariedade, de confiança, de transmissão de valores, da busca do autoconceito, na tentativa de estabelecer um significado de vida. Para criação e incentivo da imaginação, da busca do entendimento 
do inconsciente, no auxílio do encontro da criança dentro do adulto. $\mathrm{Ou}$, então, para o desenvolvimento e compreensão da linguagem oral, escrita e gestual da leitura, das influências que o contador de histórias recebe e transmite.

Posse (2004), ao falar sobre a psicoterapia junguiana direcionada a pacientes psicossomáticos, sugere o uso dos contos de fadas, da interpretação de sonhos, de imagens e mitos, uma vez que essas reflexões podem ser um enlace com o mundo e a psique do paciente psicossomático. Esse recurso favorece o diálogo e a possibilidade de socialização dos participantes, promovendo, assim, uma melhora funcional na sua comunicação.

Ferreira (1991) enfatiza o uso dos contos como dispositivos terapêuticos com pacientes em internação hospitalar, pois se mostram histórias imbuídas de afetos e mistérios, objetivando a totalidade psíquica. $\mathrm{O}$ exercício de ouvir, dialogar a respeito de uma ideia, de um sentimento, e dar expressão às imagens por intermédio de traços de desenhos é, sem dúvida, um precioso meio de reordenação e transformação, favorecendo a evolução do paciente. Fortalecida, a pessoa terá por consequência sua capacidade de socialização ampliada. Costa (2002) descreve o uso dos contos de fadas como recurso terapêutico na intervenção de crianças com câncer, pelo fato de essas histórias falarem de dificuldades humanas e tornarem mais fácil a expressão das suas angústias.

Chauí (1984), filosofa que se lança no entendimento psicanalítico dos contos de fadas, trabalha e estuda o conteúdo desses contos no atendimento a crianças vitimadas por abuso sexual. Escreve que os contos operam como uma espécie de "rito de passagem", ao auxiliarem a criança a administrar o presente, a preparar-se para adversidades futuras e a separar-se do seu mundo familiar, por consequência, seu ingresso no âmbito adulto. Elenca sua relação com a sexualidade, por abordarem as temáticas de forma ambígua. Os contos, por um vértice, permitem e estimulam o acesso aos desejos, fantasias inconscientes; por outro, reforçam os padrões de repressão sexual, pois punem os transgressores e mostram o momento adequado e desejado para a manifestação dos conteúdos sexuais, por vezes criando estereótipos de masculinidade e feminilidade.

Cyrulnik (2005) enfatiza o encantamento das crianças com narrações do tipo "era uma vez", por oferecerem uma bela passagem, uma oportunidade de felicidade, um aliciamento afetivo no qual aquele que narra faz um convite para que as aventuras verbais sejam compartilhadas com aqueles que as escutam. Ao falar da mágica viagem do "era uma vez", Cyrulnik antecipa que as crianças feridas emocionalmente encontram certa dificuldade para embarcar nessa aventura, uma vez que compartilhar uma história de infelicidades é sofrer uma 
segunda vez. Assinala que a narração oferece uma proteção ao psiquismo da criança, um reviver sua história por meio do faz de conta.

É a voz do narrador que propicia os toques mágico, lúdico e terapêutico ao ato de contar histórias, o que demanda uma química entre aquele que narra e o que escuta (Caldin, 2002). Ferro (1995) enfatiza a "trama afetiva" que a criança estabelece com o narrador. Gutfreind (2003) e Bittencourt (1991) afirmam que o encantamento que o conto de fadas produz na criança está intimamente relacionado ao fato de ela, um dia, ter-se "encantado" pela voz da mãe.

Hisada (1998) defende o uso dos contos de fadas como dispositivos de intervenção na clínica psicológica, não somente com crianças, mas também com adultos. Salienta que o uso de histórias na psicoterapia pode ser considerado uma interpretação transicional. Pacientes fazem uso das histórias como instrumento para comunicar algo. Os contos ou histórias operam como um recurso para diminuir a angústia persecutória, principalmente dos adultos, proporcionando uma maior aproximação de suas próprias dificuldades, justamente porque as histórias fazem reviver aspectos mais primitivos a partir de um contexto lúdico, beneficiando aqueles adultos que não tiveram a grata experiência com o lúdico e com o brincar e, por consequência, apresentam falhas em seu desenvolvimento.

A história é uma das possibilidades transicionais que pode enriquecer o trabalho terapêutico, afirma Hisada (1998), no encontro que se promove na sessão analítica, entre o paciente e seu analista. É nesse encontro, nesse espaço potencial, que o ilusionamento acontece, operando sobre a formação da subjetividade humana. $\mathrm{O}$ trabalho analítico que privilegia o uso de histórias opera para a melhora do padrão comunicativo do paciente. Os contos e as histórias constituem-se ótimo canal transicional, podendo ser usados como uma forma de brincar, já que, de acordo com a teoria winnicottiana, é na ação lúdica que o indivíduo cria, o que facilita o seu desenvolvimento.

Hisada (1998) questiona a aplicabilidade desse recurso com pacientes que apresentem falhas em seu processo de simbolização; cabe ao terapeuta, no entanto, a partir da transferência e da contratransferência estabelecidas, decidir usá-los ou não. Compartilha com autores como Safra (2005) e Gutfreind (2003) a preocupação quanto ao uso indiscriminado dos contos de fadas e das demais histórias infantis, não indicando seu uso no início de uma psicoterapia pelo fato de o terapeuta ainda não conhecer suficientemente seu paciente. Salienta a importância de se ter conhecimento sobre os conflitos da criança, seu processo maturacional e seu meio cultural. 
Gutfreind (2003), ao experienciar a proposta do atelier de contos, inspirase no trabalho de renomados estudiosos franceses, como Marie Bonnafé (1944), em seu trabalho com bebês e famílias marginalizadas, e em Pierre Laffourge (1955), que usa os contos como possibilidade de intervenção com crianças autistas. Gutfreind (2004) evidenciou melhoras nos transtornos de conduta apresentados pelas crianças francesas após frequentarem o atelier de contos. Demonstraram evolução significativa no seu modo de expressão, permitindo-se denunciar o sofrimento decorrente da sua separação de seus pais. $\mathrm{O}$ autor faz menção a outro estudo desenvolvido na cidade de Porto Alegre com crianças que apresentam transtornos de aprendizagem em escolas comunitárias. Situa os primeiros resultados como positivos, pois apontam como as crianças se tornaram mais atentas, menos hiperativas e mais abertas aos processos de aprendizagem.

Gutfreind $(2003,2004)$, ao abordar a função do conto como um estímulo à vida imaginária e à capacidade de simbolização, também o enfoca como um estímulo pertinente à função do pensar. Focaliza a capacidade de continência desempenhada pelo conto, conforme organiza os arcaísmos da criança, dandolhes um sentido e instigando sua capacidade de pensamento. "O potencial terapêutico de contar histórias é hoje incontestável” (Gutfreind, 2004, p. 25).

Safra (2005) apresenta o conto de fadas como uma possibilidade de intervenção na clínica psicológica, afirmando que auxilia no enfrentamento das dificuldades e no aprofundamento dos vínculos da criança com o terapeuta, assim como com seus pais. Aponta que o uso de histórias na psicoterapia mostra-se uma intervenção positiva justamente por propiciar a inclusão dos pais, "contadores no lar", no processo terapêutico da criança. Sua relevância sustenta-se também por possibilitar seu uso em trabalhos institucionais a partir de diversas perspectivas, seja em trabalhos individuais ou grupais.

Os contos podem ser usados, de forma terapêutica, como mediadores entre o mundo interno e a realidade externa da criança, como dispositivos de contenção de seus aspectos psíquicos, sendo, ainda, uma possibilidade de intervenção em seu processo de desenvolvimento. Dessa forma, a criança não necessitará refugiar-se em uma organização defensiva patológica, ou mesmo desenvolver um sintoma por meio do qual o corpo siga sofrendo em lugar da mente (Dias, 2003; Ferro, 1995; Hisada, 1998; Radino, 2001, 2003; Safra, 2005; Shepherd, Johns \& Robinson, 1997; Winnicott, Shepherd \& Davis, 2005).

Lezhava e Rtskhiladse (2006) relatam uma experiência transcorrida em um hospital, na qual os contos de fadas foram usados como instrumento lúdico- 
educativo de informação, manejo e intervenção junto a um grupo de crianças que sofrem de asma brônquica. Afirmam que o uso dos contos facilitou a evolução do tratamento e a profilaxia da doença, visto que, por intermédio deles, parece mais fácil e natural para as crianças aceitarem sua doença e conviverem com ela. Salientam, ainda, que esse método de informação e conduta na abordagem de crianças asmáticas mostrou-se mais eficaz que os apresentados por tratamentos tradicionais.

Goulart (2003) ressalta a necessidade de as crianças portadoras de doenças crônicas participarem de espaços nos quais possam falar de suas experiências, dúvidas e angústias. A autora aponta ainda para a eficácia da intervenção com grupos específicos, como o de crianças asmáticas, nos quais as narrativas são dispositivos para dar significado, organizar e ressignificar sua experiência. Nas narrativas grupais, muitas vezes não são narradas histórias de vida, mas são veiculadas histórias de uma vida alterada pela doença.

Constatamos, portanto, que a literatura nacional e internacional oferece subsídios, resgatando a veiculação secular dos contos de fadas pelas mais diversificadas culturas e geraçôes, encantando adultos e, sobretudo, crianças. Remete-nos a sua constituição histórica e artesanal no Período Medieval, principalmente, até a atualidade, imortalizando narradores e escritores que contribuíram significativamente para o registro dessas histórias de origem popular. $\mathrm{Na}$ clínica psicanalítica, destaca-se o crescente uso dos contos como instrumentos terapêuticos em oficinas na área da saúde (Gutfreind, 2003; Schneider, 2008; Torossian, 2008) e percebe-se uma congruência entre a narrativa dos contos de fadas e a de histórias de vida.

\section{Referências}

Ariès, P. (1981). História social da criança e da família. Rio de Janeiro: Livros Técnicos e Científicos.

Bernstein, A. C. (1999). Reconstructing the Brothers Grimm: new tales for step-family life. Family Process, 38 (4), 415-29.

Bettelheim, B. (1980). A psicanálise dos contos de fadas. 19. ed. Rio de Janeiro: Paz e Terra.

Bittencourt, A. M. L. (1991). Encantos e desencantos dos contos de fada. In: J. Outeiral \& R. B. Graña. Donald Winnicott estudos (p. 136-149). Porto Alegre: Artes Médicas.

Brandt, L. M. (1983). The fairy tale as paradigm of the separationindividuation crisis: implications for treatment of borderline adolescent. Adolescent Psychiatry, 11, 75-91. 
Bruder, M. (2004). Implicancias del cuento terapêutico em el bienestar psicológico en mujeres y sus correlatos. Psic, 5 (2), 14-21.

Caillé, P. \& Rey, Y. (1988). Habia una vez...: del drama familiar al cuento sistémico. Buenos Aires: Nueva Visión.

Caldin, C. F. (2002). A oralidade e a escritura na literatura infantil: referencial teórico para a hora do conto. Encontros Bibbi: Revista Eletrônica de Biblioteconomia e Ciência da Informação, 13, 1-14.

Caldin, C. F. (2004). A aplicabilidade de textos literários para crianças. Encontros Bibbi: Revista Eletrônica de Biblioteconomia e Ciência da Informação, 18, 72-89.

Cashdan, S. (2000). Os sete pecados capitais nos contos de fadas: como os contos podem influenciar nossas vidas. Rio de Janeiro: Campos.

Castello, M. (1999). Groupe d'études de psychiatrie, psychologie et sciences sociales. Perspectives Psychiatriques, 38(5), 353-356.

Catheline-Antipoff, N. \& Soulayrol, R. (1994). Rôle de l'animal dands la literature enfantine: clinique, sémiologie et thérapeutique. Psychologie Médicale, 26, 1457-1459.

Chauí, M. (1984). Contos de fadas. In: M. Chauí. Repressão sexual: essa nossa (des)conhecida. (p. 32-54). São Paulo: Brasiliense.

Corso, D. L. \& Corso, M. (2006). Fadas no divã: psicanálise nas histórias infantis. Porto Alegre: Artmed.

Corso, D. L. \& Corso, M. (2005). A infância invade o conto de fadas. Cadernos da Appoa, 134, 43-48.

Costa, C. L. (2002). Câncer infantil: a realidade da doença na fantasia dos contos de fadas. Acta Oncológica Brasileira, 22(2), 292-294.

Cyrulnik, B. (2005). Murmúrio dos fantasmas. São Paulo: Martins Fontes

Davies, E. (1988). Reframing, metaphors, myths and fairy-tales. Journal of Family Therapy, 10 (1), 83-92.

Dias, E. O. (2003). A teoria do amadurecimento de D. Winnicott. Rio de Janeiro: Imago.

Dieckmann, H. (1986). Contos de fadas vividos. São Paulo: Paulinas. 
Dieckmann, H. (1997). Fairy tales in psychotherapy. The Journal of Analytical Psychology, 42 (2), 253-268.

Ellis, E. M. (1990). Adult agoraphobia and childhood separation anxiety: using children's literature to understand the link. American Journal of Psychotherapy, 44 (3), 433-440.

Erle, X. E. (1999). Lineas de investigation en literatura infantile y juvenile. Revista de Psicodidática, 9, 2-9.

Fagulha, T. (1999). Era uma vez... um menino com medo de morrer. Revista Portuguesa de Psicossomática, 1 (1), 89-100.

Ferreira, M. P. (1991). Contos de fada como atividade terapêutica. Jornal Brasileiro de Psiquiatria, 40 (4), 160-162.

Ferro, A. (1995). A técnica na psicanálise infantil: a criança e o analista da relação ao campo emocional. Rio de Janeiro: Imago.

Figueiredo, T. A. (1998). A magia dos contos de fadas. Ciclo de Seminários sobre o jogo simbólico. Brasília: Associação Pró-educação Vivendo e Aprendendo. Disponívelem: $<$ http://inforum.insite.com.br/arquivos/1027/Taicy_-_CONTOS_ DE_FADA.doc $>$.

Garcia, A. L. A. \& Garcia, S. C. (2005). Análise ideológica, crítica e comparativa dos contos: Chapeuzinho Vermelho de Grimm e Chapeuzinho Amarelo de Chico Buarque. Claretiano: Revista do Centro Universitário Batatais, 1 (5), 18-22.

Góes, L. P. (1991). Introdução à literatura infantil e juvenil. 2. ed. São Paulo: Pioneira.

Goldmann, D. (2001). Factured fairy tales: commentary on paper by Susan Fairfield. Psychoanalytic Dialogues, 11 (2), 269-281.

Goulart, C. M. T. (2003). Histórias de crianças: as narrativas de crianças asmáticas no brincar. Psicologia Reflexão e Crítica, 16 (2), 355-365.

Gutfreind, C. (2000). The use of the fairy tale as a means of treating children who have been separated on a long-term basis from their parents: therapeutic possibilities and specific aspects. Neuropsychiatrie de I'Enfance et de I'Adolescence, 48 [abstract].

Gutfreind, C. (2002). A utilização terapêutica do conto: uma pesquisa clínica. Revista Brasileira de Psicoterapia, 4 [abstract].

Gutfreind, C. (2003). O terapeuta e o lobo: a utilização do conto na psicoterapia da criança. São Paulo: Casa do Psicólogo. 
Gutfreind, C. (2004). Contos e desenvolvimento psíquico. Viver Mente \& Cérebro, 142, 24-29.

Hillesheim, B. (2006). Contos de fadas e infância(s). Educação e Realidade, 3 (1), 107-126.

Hisada, S. (1998). A utilização de histórias no processo psicoterápico: uma visão winnicottiana. Rio de Janeiro: Revinter.

Hisada, S. (2003). Conversando sobre psicossomática. Rio de Janeiro: Revinter.

Ishikawa, T. et al. (1990). A study of communication and behavior management in pediatric dentistry: approach to the child using the fairy tales. Shoni Shikagaku Zasshi: The Japonese Journal of Pedodontics, 28 (4), 1084-1092.

Lezhava, D. A. \& Rtskhiladse, I. G. (2006). Fairy tales as a method of education of children with bronchial asthma. Pediatric Pulmonology, 24 (Suppl. 16), 308.

Lima, T. A. C. (2000). A função simbólica das histórias infantis e as fantasias inconscientes. Psicopedagogia on-line. Disponível em: <http://www. psicopedagogia. com.br/artigos/artigo.asp? entrID=266>. (Acesso em: 20 nov. 2007).

Lubetsky, M. J. (1989). The magic of fairy tales: psychodynamic and developmental perspectives. Child psychiatry and human development, 19 (4), 245-255.

Luz, A. M. H. \& Zanetti, L. (2003). The fairy tale and modern paternity. Revista Brasileira de Enfermagem, 56 (3), 292-297.

Machado, M. M. (1988). A propósito dos contos de fadas. Pediatria São Paulo, 10 (4), 196-197.

Melli, R. \& Giglio, J. (1999). “Enquanto o seu lobo não vem...” Contos de fadas na escola? Relato de uma experiência. Psico-USF, 4 (1), 13-23.

Monaci, E. M. (1990). Mitos, contos, lendas e fábulas: fantasia versus realidade. Revista Brasileira de Pesquisa em Psicologia, 2 (2), 42-54.

Oliveira, C. M. (2001). Presença da fada madrinha nas versões do conto Cinderela. Disponível em: <http://www.graudez.com.br/litinf/trabalhos/ contosdefadas.htm>. (Acesso em: 19 set. 2006).

Oliveira, F. O. (1993). Contos de fada. Revista de Psicologia Plural, (5), 13-16. 
Posse, M. (2004). Psicoterapia jungiana para la somatización. The European Journal of Psychiatry, 18 (1), 23-30.

Radino, G. (2001). Oralidade, um estado de escritura. Psicologia em Estudo, 6 (2), 73-79.

Radino, G. (2003). Contos de fadas e a realidade psíquica: a importância da fantasia no desenvolvimento. São Paulo: Casa do Psicólogo.

Roberge, L. (2002). Séparation, recomposition famileale et rivalité fraternelle. Psyychologie Quebéc, 24-26.

Robinson, J. G. (1986). Fairy tales and teaching family therapy. Journal of Family Therapy. 8(4), 383-393.

Robinson, O. (2004). Rymes and reasons in the Grimms Kinder und hausmarchen. The German Quarterly, 77 (1), 47-58.

Safra, G. (2005). Curando com histórias. São Paulo: Sobornost.

Schmid, G. B. et al. (2002). Phantasy therapy in psychiatry: rediscovering reality in phantasy: a special treatment for in- and outpatients in general psychiatry. Research in Complementary an Natural Classical Medicine, 9 (5), 283-291.

Schneider, R. (2008). Oficina de contos de fadas: uma intervenção com crianças asmáticas, a partir do enfoque Winnicottiano. Dissertação de mestrado, Programa de Pós-graduação em Psicologia Clínica, Universidade do Vale do Rio dos Sinos - Unisinos, São Leopoldo.

Shepherd, R.; Johns. J. \& Robinson, H. (1997). D. W. Winnicott: pensando sobre crianças. Porto Alegre: Artes Médicas.

Silva, A. M. (2004). O conto de fada e a problemática do pertencimento social. Revista Espaço Acadêmico, 4 (39), 1-5.

Silva, M. E. \& Fachin, G. R. B. (2002). Leitura para portadores de deficiência com necessidades especiais: relato de uma experiência. Revista ACB: Biblioteconomia em Santa Catarina, 7 (1), 148-156.

Souyouldzoglou, M.; Anasiassia, A.; Coulacoglou, C. \& Gardiner. (1999). Profil de la personnalité d'enfants présentant dês problèmes dans leur apprentissage: utilisation du test des contes de fées. Psychologie et Psychométrie, 20 [abstract].

Souza, M. T. C. C. (2005). Valorizações afetivas nas representações de contos de fadas: um olhar piagetiano. Boletim de Psicologia, 55 (123), 1-22. 
Stube, S. (2001). Das märchen-stegreisfpiel: Eine erlebnisorientierte gruppenarbeit. Psych Pflege, 7 (3), 124-128.

Sussenbacher, G. (1982). Die verwendung eines Marchenentwurfes zur auflosung einer pathogenen doppelbindung: fallbericht zur behandlung einer windphobie. Praxis der Kinderpsychologie und Kinderpsychistrie, 31 (5), 185-190.

Torossian, S. D. (2008). Contar para viver: o início de uma trama. Cadernos da Appoa, 168, 37-50.

Turkel, A. R. (2002). From victim to heroine: children's stories revisited. Journal American Academy of Psychoanalysis, 30 (1), 71-81.

Tychey, C. (1993). Comparative genetic approach to the study of body image of children from 4 to 14 years of age using the fairy tale of the ant. Perceptual and Motor Skills, 76 (2), 1179-1189.

Winnicott, C.; Shepherd, R. \& Davis, M. (2005). Explorações psicanalíticas D. W. Winnicott. Porto Alegre: Artmed.

Zago, J. A. (1998). Drogadição, self, contos de fadas e recursos terapêuticos: um ponto de vista fenomenológico existencial. Informação Psiquiátrica, 2 (17), 67-71.

Zilberman, R. (1998). A literatura infantil na escola. 10. ed. São Paulo: Global. 